\title{
High molecular weight SOA formation during limonene ozonolysis: insights from ultrahigh-resolution FT-ICR mass spectrometry characterization
}

\author{
S. Kundu ${ }^{1,2}$, R. Fisseha ${ }^{3}$, A. L. Putman ${ }^{3}$, T. A. Rahn $^{3}$, and L. R. Mazzoleni ${ }^{1,2}$ \\ ${ }^{1}$ Department of Chemistry, Michigan Technological University, Houghton, MI 49931, USA \\ ${ }^{2}$ Atmospheric Science Program, Michigan Technological University, Houghton, MI 49931, USA \\ ${ }^{3}$ Earth and Environmental Sciences, Los Alamos National Laboratory, Los Alamos, NM 87545, USA \\ Correspondence to: L. R. Mazzoleni (lrmazzol@mtu.edu)
}

Received: 5 January 2012 - Published in Atmos. Chem. Phys. Discuss.: 24 January 2012

Revised: 16 May 2012 - Accepted: 24 May 2012 - Published: 25 June 2012

\begin{abstract}
The detailed molecular composition of laboratory generated limonene ozonolysis secondary organic aerosol (SOA) was studied using ultrahigh-resolution Fourier transform ion cyclotron resonance (FT-ICR) mass spectrometry. Approximately 1200 molecular formulas were identified in the SOA over the mass range of 140 to $850 \mathrm{Da}$. Four characteristic groups of high relative abundance species were observed; they indicate an array of accretion products that retain a large fraction of the limonene skeleton. The identified molecular formulas of each of the groups are related to one another by $\mathrm{CH}_{2}, \mathrm{O}$ and $\mathrm{CH}_{2} \mathrm{O}$ homologous series. The $\mathrm{CH}_{2}$ and $\mathrm{O}$ homologous series of the low molecular weight $(\mathrm{MW})$ SOA $(m / z<300)$ are explained with a combination of functionalization and fragmentation of radical intermediates and reactive uptake of gas-phase carbonyls. They include isomerization and elimination reactions of Criegee radicals, reactions between alkyl peroxy radicals, and scission of alkoxy radicals resulting from the Criegee radicals. The presence of compounds with 10-15 carbon atoms in the first group (e.g. $\mathrm{C}_{11} \mathrm{H}_{18} \mathrm{O}_{6}$ ) provides evidence for SOA formation by the reactive uptake of gas-phase carbonyls during limonene ozonolysis. The high MW compounds $(\mathrm{m} / \mathrm{z}>300)$ were found to constitute a significant number fraction of the identified SOA components. The formation of high MW compounds was evaluated by molecular formula trends, fragmentation analysis of select high MW compounds and a comprehensive reaction matrix including the identified low MW SOA, hydroperoxides and Criegee radicals as building blocks. Although the formation of high MW SOA may oc-
\end{abstract}

cur via a variety of radical and non-radical reaction channels, the combined approach indicates a greater importance of the non-condensation reactions over aldol and ester condensation reaction channels. Among these hemi-acetal reactions appear to be most dominant followed by hydroperoxide and Criegee reaction channels.

\section{Introduction}

Organic aerosols constitute up to $90 \%$ of the aerosol mass fraction and are known to have adverse impacts on visibility, climate, public health and biogeochemistry (Kanakidou et al., 2005; Salma et al., 2008). Total global biogenic secondary organic aerosols (SOA) are estimated to be 12 $70 \mathrm{Tg} \mathrm{yr}^{-1}$, greatly exceeding the $2-12 \mathrm{Tg} \mathrm{yr}^{-1}$ of anthropogenic SOA (Hallquist et al., 2009). Since the discovery of aerosol formation from biogenic volatile organic compounds (Went, 1960), significant research has been conducted on the composition of SOA and their formation processes. An improved understanding of the molecular composition and formation processes of SOA is required for a quantitative assessment of its production, properties and environmental effects (Fuzzi et al., 2006). The major biogenic volatile organic compounds consist of isoprene followed by monoterpenes and sesquiterpenes (Liao et al., 2007). Limonene accounts for $\sim 20 \%$ of total monoterpene emissions into the atmosphere by vegetation (Stroud et al., 2005). Despite its low concentration, limonene has high potential to form SOA 
because of the presence of an endocyclic and an exocyclic bond. The aerosol yields of limonene ozonolysis are several times higher than those of $\alpha$-pinene ozonolysis (Iinuma et al., 2004; Leungsakul et al., 2005; Heaton et al., 2007). Thus due to the significant emissions and higher reactivity of limonene, limonene oxidation may contribute substantially to aerosol organics. Despite their significance, little is known about the molecular composition of biogenic SOA and their formation processes.

Current studies indicate that high MW SOA components are accretion products of low MW components. Therefore, the low MW compounds are often considered to be building units of high MW compounds. To improve our understanding of this process, comprehensive characterization of the low MW SOA components is needed. Several compounds in the mass range of $168<m / z<202$ were detected by Leungsakul et al. (2005) and Geddes et al. (2010) in limonone ozonolysis SOA using a gas chromatography/mass spectrometry (GCMS) and near-infrared laser desorption/ionization aerosol mass spectrometry (NIR-LDI-AMS). They described the formation of the observed compounds with elimination and isomerization reactions of Criegee radicals. In another study using high resolution mass spectrometry, Walser et al. (2008) observed a higher number of low MW components in SOA from limonene ozonolysis. They described the formation of additional compounds with alkyl peroxy and alkoxy radical reactions. Despite the additional pathways, the observed $\mathrm{CH}_{2}$ and $\mathrm{O}$ homologous series (Walser et al., 2008; Bateman et al., 2009) of low MW components were not fully explained. This suggests a need to characterize the SOA products in more detail and to revisit the reaction schemes for the formation of low MW SOA.

As stated previously, high MW SOA components can be formed by the reactions of low MW neutral molecules with hydroperoxides or Criegee radicals (Ziemann, 2005; Docherty et al., 2004). High MW SOA can also be formed by hemi-acetal, aldol condensation and ester condensation reaction channels (Iinuma et al., 2004; Gao et al., 2004; Kalberer et al., 2004; Hamilton et al., 2006; Surratt et al., 2006). Recently, Sadezky et al. (2008) observed high MW compound formation by gas accretion of Criegee radicals. Heaton et al. (2007) observed the formation of high MW SOA within 3-22 s after ozone and limonene were introduced into a flow reactor. They interpreted the high MW SOA production to result from the hydroperoxide and Criegee reaction channels with a predominance of hydroperoxide reactions. In another study, Bateman et al. (2009) suggested the importance of the Criegee and hemi-acetal reaction channels for high MW SOA formation in limonene ozonolysis. The hemi-acetal and condensation reaction channels have also been proposed for the formation of high MW SOA from other monoterpenes (Iinuma et al., 2004; Reinhardt et al., 2007), and isoprene (Surratt et al., 2006). The variety of reaction channels and conclusions prompt a need for further evaluation of the relative significance of the proposed reaction channels with re- spect to the formation of a complex array of high MW SOA $(300>m / z>800)$.

A number of approaches to interpret the observed SOA molecular composition and high MW compound formation have been described in the literature. Condensation mechanisms were interpreted to be more significant by Reinhardt et al. (2007) because of the observed decrease in the O:C ratios with increasing MW in $\alpha$-pinene ozonolysis SOA. Elemental ratios were also reported by Putman et al. (2011), they observed a similar decrease in the $\mathrm{O}: \mathrm{C}$ ratios with increasing MW in $\alpha$-pinene ozonolysis SOA but a corresponding decrease in the $\mathrm{H}: \mathrm{C}$ ratios with increasing $\mathrm{MW}$ was not observed. Both of the elemental ratios $(\mathrm{O}: \mathrm{C}$ and $\mathrm{H}: \mathrm{C})$ are expected to decrease with the elimination of water in the condensation reactions. The decrease in the O:C with increasing $\mathrm{MW}$ is in contrast to the interpretation by Jimenez et al. (2009). Using aerosol mass spectrometry, they report highest O:C ratios for low-volatility OOA (oxygenated organic aerosol), which likely contained a large fraction of oligomeric and other high MW products. Bateman et al. (2009) observed a predominance of double bond equivalents $(\mathrm{DBE}=$ the number of rings plus the number of double bonds; McLafferty and Turecek, 1993) to increase by 2 for each of the SOA groups (monomers, dimers and trimers). DBE differences of 2 between the groups are expected for the products of Criegee, hydroperoxide and hemi-acetal reaction channels. DBE differences of 3 between the groups are expected for the products of condensation reactions. A complex array of building units with different DBE values may result in a complex array of high MW compounds with various DBE values. These results suggest a need for additional investigation to explain the high MW compound formation. To evaluate the reaction channels, Heaton et al. (2007) created a reaction matrix of building units to explain the observed high MW compound formation in monoterpene ( $\beta$-pinene, carene, limonene and sabinene) ozonolysis SOA. This approach resulted in individual high MW compounds formed by different reaction channels.

Here we present the results of ultrahigh-resolution FT-ICR MS analysis with a resolving power of 400000 to characterize limonene ozonolysis SOA. Reaction channels and their relative significance for the formation of high MW SOA components are discussed. Fragmentation analyses with ultrahigh resolution mass analysis were carried out for structural elucidation and further insights toward an improved understanding of the formation of high MW limonene ozonolysis SOA.

\section{Experimental}

\subsection{SOA generation and extraction}

Aerosol samples were generated by the reaction of ozone and (R)-(+)-limonene (99\%, Sigma-Aldrich) at the Los 
Alamos National Laboratory in an aerosol chamber. Briefly, the aerosol chamber is a $1.5 \mathrm{~m}^{3}$ flexible Teflon bag (thickness: $5 \mathrm{~mm}$ ) suspended on a bench top. The chamber was covered with a black fabric to simulate dark conditions. Before the start of the experiment, the chamber was cleaned by flushing it with purified compressed air (prepared by the Los Alamos National Laboratory gas facility) until the particle number was $<2$ particles $\mathrm{cm}^{-3}$. Compressed air was purified by passing it through a water trap (Drierite) and hydrocarbon trap (Restek). A condensation particle counter (CPC, TSI 3025A) was used to determine the number of particles. Prior to introduction of reactants, the relative humidity was adjusted to 0 or $4 \%$ and was recorded by a relative humidity sensor (Vaisala Combined Pressure, Humidity and Temperature Transmitter, PTU300). Aerosols were generated under dry conditions to reduce the complexity of SOA formation (Jonsson et al., 2008). Limonene vapor was introduced through a heated port and was allowed to disperse throughout the chamber for $15 \mathrm{~min} .4 \mu \mathrm{l}$ of liquid limonene was injected into the heated port to produce the target concentration of $500 \mathrm{ppb}$. Ozone was produced until a maximum concentration of $250 \mathrm{ppb}$ was achieved (Ozone monitor, 2B Technologies, Model 205). Seed aerosols and hydroxyl radical scavengers were not added to the experiment. A heat mat maintained at $25-28^{\circ} \mathrm{C}$ was used below the chamber to mix the reactants homogeneously throughout the chamber. Aerosol particles were observed within seconds after ozone was introduced to the chamber. The reactants were allowed to react for an hour. The particle number concentration reached $\sim 20000$ particles $\mathrm{cm}^{-3}$. The resulting aerosols were collected with a flow rate of $6 \mathrm{slpm}$ for $2.5-5 \mathrm{~h}$ onto a prebaked quartz fiber filter $\left(600^{\circ} \mathrm{C}\right.$ for $>8 \mathrm{~h} ; 47 \mathrm{~mm}$ diameter $)$. A denuder was not used for the aerosol collection. Chamber blanks were collected following the same methods except limonene and ozone were not introduced into the chamber. The sampled filters were stored in petri dishes (Pall Corporation) wrapped with aluminum foil at $-20^{\circ} \mathrm{C}$. The petri dishes were sealed using aluminum foil to prevent the intrusion of gaseous compounds. Blue ice was used to keep the samples cold during transport between laboratories. Half of the filter was extracted with $5 \mathrm{ml}$ of a 1:1 mixture of acetonitrile (Chromasolv, Sigma Aldrich) and water (ACS, Sigma Aldrich). Acetonitrile is not expected to react with analyte molecules (Bateman et al., 2008). However, water may hydrate analyte molecules potentially altering the functional groups. The extraction was carried out in a sonicating bath for $30 \mathrm{~min}$. Recovery and extraction artifacts were not evaluated. Extracts were filtered and stored at $-20^{\circ} \mathrm{C}$ until analysis.

\subsection{Ultrahigh-resolution FT-ICR-MS analysis}

Samples were analyzed with a hybrid 7T FT-ICR-MS (LTQ FT Ultra, Thermo Scientific) equipped with an electrospray ionization (ESI) source. The instrument was externally cal- ibrated in the negative ion mode with standard solutions of sodium dodecyl sulfate and taurocholic acid and the resulting mass accuracy was better than $2 \mathrm{ppm}$. Diluted samples were infused at $5 \mu \mathrm{min}^{-1}$ into the ESI interface. The adjustable ESI probe was placed in position "B" for stable electrospray ionization. The needle voltage was set between -3.7 and $-4.0 \mathrm{kv}$ and no sheath gas was used. Mass resolving power was set at $400000(\mathrm{~m} / \mathrm{z}, 400)$ for all spectra. The capillary temperature was maintained at $265^{\circ} \mathrm{C}$. Mass spectra of $m / z, 100-1000$ were acquired in the negative ion mode. Note that lower intensities of low MW ions $(\mathrm{m} / \mathrm{z}<200)$ relative to higher ones were observed in the spectra of the FTICR MS compared to the LTQ MS. The difference between the spectra is likely indicative of ion losses over the $\sim 1 \mathrm{~m}$ ion transfer path between the mass analyzers of the hybrid LTQ/FT-ICR MS instrument (M. C. Soule, personal communication, 2011). Automatic gain control was used to consistently fill the mass analyzers with the same number of ions $\left(n=1 \times 10^{6}\right)$ for each acquisition and to avoid space charge effects associated with over-filling the mass analyzer (Soule et al., 2010).

Tandem mass analysis (MS/MS) of selected precursor ions was performed within the FT-ICR mass analyzer using infrared multi-photon dissociation (IRMPD). Target precursor ions were isolated in the linear ion trap with an isolation width of $2 \mathrm{Da}$ and were then transferred to the FT-ICRMS. The isolated ions were irradiated with the full energy of the IRMPD light source $\left(20 \mathrm{~W} \mathrm{CO}_{2}\right.$ laser) over $300 \mu \mathrm{s}$. The MS/MS spectra were measured with a resolving power of $200000(\mathrm{~m} / \mathrm{z}, 400)$ and 50 transients were acquired to produce product ion mass spectra.

\subsection{Molecular formula assignment and quality control}

Approximately 200 individual time domain transients were co-added with Sierra Analytics Composer software (Mazzoleni et al., 2010). Co-addition of numerous time domain transients prior to Fourier transformation improves the signal-to-noise ratio (Kujawinski et al., 2002) and the signal reproducibility (Soule et al., 2010). Several high relative abundance SOA components were used as internal recalibrants (Sleighter et al., 2010; Putman et al., 2011) to improve analyte mass accuracy. A full list of internal recalibrants is given in Supplement Table S1. The molecular formula calculator was set to allow up to 100 carbon, 200 hydrogen, and 20 oxygen atoms per molecular composition. Unequivocal formula assignments are expected for masses up to $1000 \mathrm{Da}$ when only C, H and O are included (Koch et al., 2005). Data filtering of the assigned formulas was done by applying rules and assumptions as described in Koch et al. (2005). DBE was calculated from Eq. (1) (McLafferty and Turecek, 1993):

$\mathrm{DBE}=c-h / 2+n / 2+1$ 
for elemental composition $\mathrm{C}_{c} \mathrm{H}_{h} \mathrm{~N}_{n} \mathrm{O}_{o} \mathrm{~S}_{s}$. Note that sulfur is divalent in Eq. (1). Additional bonds formed by tetravalent and hexavalent $\mathrm{S}$ are not included in DBE calculations.

Soule et al. (2010) have shown that ion detection and detector response of the ion intensities in the ESI FT-ICR mass spectra are somewhat variable between replicate analyses. Their reproducibility is improved with the co-addition of 200 transients at a resolving power of 400000 . Only the common ions after replicate analyses of the SOA samples with nearly identical parameters were retained to be presented in this work. More than $80 \%$ of the ions were common between replicate analyses of the SOA sample generated at $0 \%$ relative humidity and more than $85 \%$ of the ions were common between the two experimental SOA samples generated at 0 and $4 \%$ relative humidity. The comparison is shown in Figs. S1 and S2. A full list of the retained molecular formulas is given in Table S1. About $20 \%$ of the ions were common between blanks and aerosol samples. Blank subtraction was not applied because the intensity in the blank sample was less than $6 \%$ of that in the experimental SOA samples. The lower intensity of common ions suggests they resulted from carry-over within the ESI source.

\section{Results and discussion}

\subsection{General characteristics of the SOA mass spectra}

Approximately 1200 monoisotopic molecular formulas were identified in limonene ozonolysis SOA samples. Molecular formulas containing ${ }^{13} \mathrm{C}$ were identified and corresponded to molecular formulas providing an intrinsic validation of formula assignment (Schaub et al., 2005). The high number of molecular formulas identified in this study is associated with an increased sensitivity of the LTQ FT U1tra (Thermo Scientific) and the co-addition of $\sim 200$ transients (Kujawinski et al., 2002). The limonene ozonolysis SOA mass spectra has four prominent clusters of high relative abundance ions. This type of clustering of high relative abundance ions was previously observed in the soft ionization mass spectra of SOA from limonene ozonolysis and other terpene ozonolysis (Reinhardt et al., 2007; Tolocka et al., 2006; Walser et al., 2008). In the previous studies the SOA components within each of the clusters are referred to as monomers, dimers, trimers and tetramers. Due to the complex array of SOA components within each of the clusters, we refer to them as groups: Group I $(140<m / z<300)$, Group II $(300<m / z<500)$, Group III $(500<m / z<700)$ and Group IV (700<m/z<850) (Supplement Fig. S3). Mass differences between the ions within clusters are associated with the exact masses of $\mathrm{CH}_{2}$ and $\mathrm{O}$. Similar mass differences were observed in the mass spectra of SOA from limonene and $\alpha$-pinene ozonolysis (Tolocka et al., 2004; Walser et al., 2008; Bateman et al., 2009).

\subsection{Characteristics and formation of low MW SOA}

Consistent with previous studies (Heaton et al., 2007; Tolocka et al., 2004), Group I $(140<m / z<300)$ compounds are considered to be the building units of high MW SOA. Group I includes 74 identified molecular formulas with relative abundances $>1 \%$ (Fig. 1). The highest relative abundance ions are at the nominal masses of $\mathrm{m} / \mathrm{z} 185$ and $\mathrm{m} / \mathrm{z} 245$, followed by nominal masses of $\mathrm{m} / \mathrm{z} 261, \mathrm{~m} / \mathrm{z} 231, \mathrm{~m} / \mathrm{z} 215$, $\mathrm{m} / \mathrm{z} 217, \mathrm{~m} / \mathrm{z} 171, \mathrm{~m} / \mathrm{z} 217, \mathrm{~m} / \mathrm{z} 199$ and $\mathrm{m} / \mathrm{z} 247$. Note that the relative abundances in the negative ion mass spectra might be influenced by the ionization efficiency of analytes. A number of $\mathrm{CH}_{2}, \mathrm{O}$ and $\mathrm{CH}_{2} \mathrm{O}$ homologous series of compounds were observed. The chemical characteristics $(\mathrm{O}: \mathrm{C}$ ratios, $\mathrm{H}: \mathrm{C}$ ratios, $\mathrm{DBE}$ and $\mathrm{OM}: \mathrm{OC}$ ratios) of the groups are described in Table 1.

Several homologous series with carbon atom number ranges of 7-15 and oxygen atom number ranges of 3-9 were observed (Fig. 1). Such diverse homologous series cannot be explained by only the oxygen-increasing-reactions and single scission of alkoxy radicals as proposed by Walser et al. (2008). In the oxygen-increasing-reactions, the alkoxy radical $\left(\mathrm{I}, \mathrm{C}_{10} \mathrm{H}_{15} \mathrm{O}_{3}\right)$ resulting from the limonene ozonolysis converts to another alkoxy radical (II, $\mathrm{C}_{10} \mathrm{H}_{15} \mathrm{O}_{4}$ ) with one more oxygen atom following the isomerization, oxygen addition and $\mathrm{RO}_{2}$ radical reactions (Fig. 2a). In the scission step, the carbon atom number is decreased with or without a change in the number of oxygen atoms. Additionally there must exist a process which can increase the carbon atom number above 10 , since several highly abundant compounds were observed. Thus, the $\mathrm{CH}_{2}$ homologous series formation is explained by: (a) multistep oxygen-increasingreactions of alkoxy radicals followed by scission of alkoxy radicals; (b) scission of alkoxy radicals followed by its multistep oxygen-increasing-reactions; and (c) reactive uptake of the gas phase carbonyls.

The relative abundances of the $\mathrm{CH}_{2}$ homologous series with DBE values of 3 are dominant in the Group I mass spectra (Fig. 1c). If the oxygen-increasing-reactions are repeated on radical (II), alkoxy radicals with more oxygen, such as those labeled III $\left(\mathrm{C}_{9} \mathrm{H}_{13} \mathrm{O}_{8}\right), \mathrm{IV}\left(\mathrm{C}_{10} \mathrm{H}_{15} \mathrm{O}_{8}\right), \mathrm{V}\left(\mathrm{C}_{9} \mathrm{H}_{13} \mathrm{O}_{6}\right)$, and $\mathrm{VI}\left(\mathrm{C}_{10} \mathrm{H}_{15} \mathrm{O}_{6}\right)$ in Fig. 2, can be produced. Alkoxy radicals such as those labeled as III and IV can be cleaved at the $\alpha$-position of the alkoxy radical to form alkyl radicals with lower carbon numbers, which may form alkoxy radicals due to their reactions with $\mathrm{O}_{2}$ and $\mathrm{RO}_{2}$. Due to the subsequent $\mathrm{RO}_{2}$ radical reactions on these alkoxy radicals, the following neutral molecules are formed including $\mathrm{C}_{7} \mathrm{H}_{10} \mathrm{O}_{6}$, $\mathrm{C}_{8} \mathrm{H}_{12} \mathrm{O}_{6}, \mathrm{C}_{9} \mathrm{H}_{14} \mathrm{O}_{6}$ and $\mathrm{C}_{10} \mathrm{H}_{16} \mathrm{O}_{6}$. They constitute the homologous series $\mathrm{C}_{7} \mathrm{H}_{10} \mathrm{O}_{6}\left(\mathrm{CH}_{2}\right)_{0-5}$ (Fig. 1c). Note the molecular formula $\mathrm{C}_{11} \mathrm{H}_{18} \mathrm{O}_{6}$ corresponding to $\mathrm{m} / \mathrm{z} 245$, is the most prominent ion in the mass spectra (Fig. S3). This compound and others are likely formed by the reactive uptake of gas-phase carbonyls (e.g., formaldehyde, acetaldehyde, acetone, glyoxal, methylglyoxal, etc.) generated from 


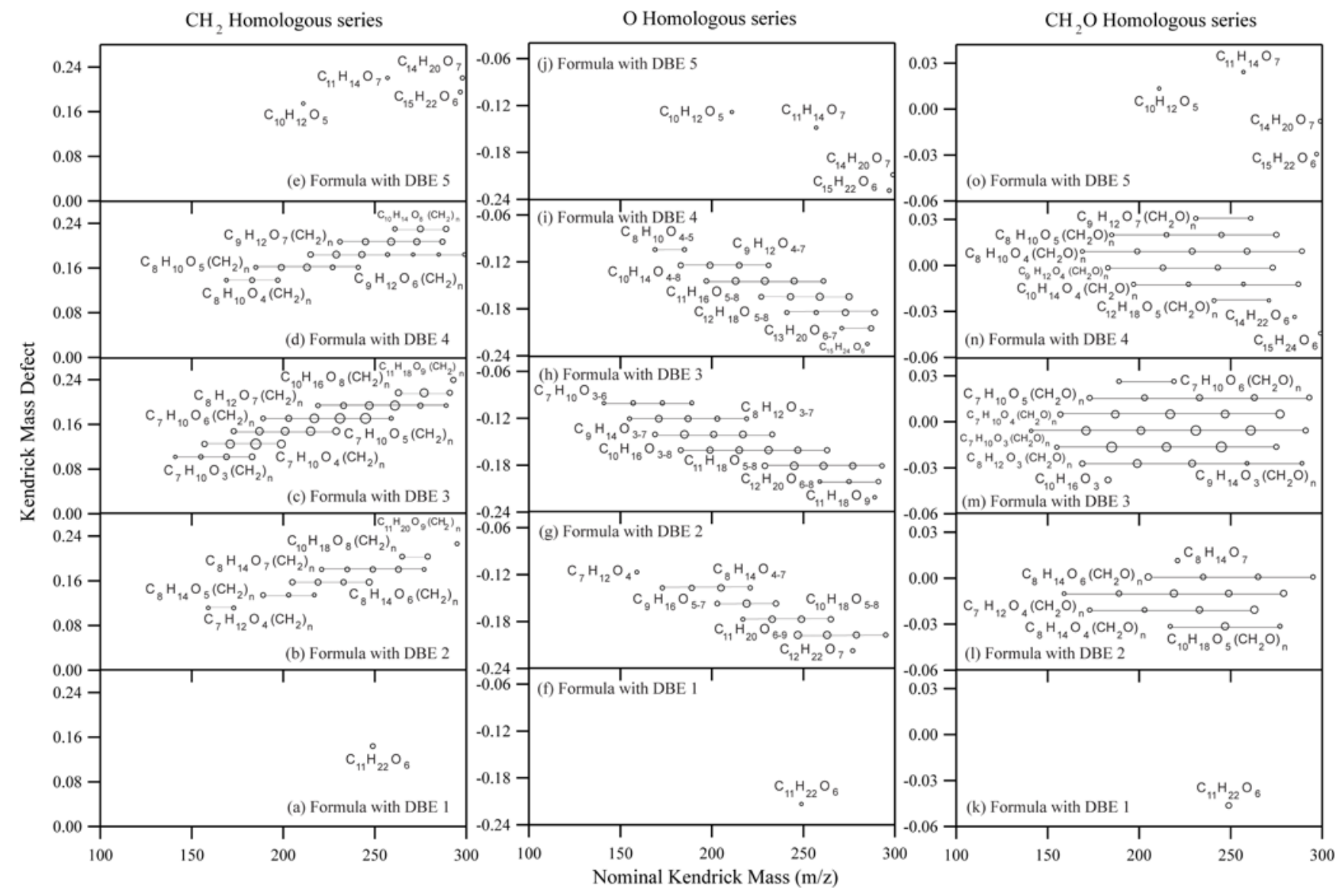

Fig. 1. $\mathrm{CH}_{2}, \mathrm{O}$ and $\mathrm{CH}_{2} \mathrm{O}$ homologous series of negative ions with $\geq 1 \%$ relative abundance for the mass range of $140<m / z<300$. Components of the homologous series fall onto the horizontal lines. Data points were scaled according to the logarithm of their measured relative abundances. The value of " $n$ " starts from zero.

Table 1. Chemical characteristics of the groups of compounds observed in the mass spectra.

\begin{tabular}{|c|c|c|c|c|c|c|c|c|}
\hline \multirow[t]{2}{*}{ Compounds } & \multicolumn{2}{|c|}{$\mathrm{O}: \mathrm{C}$} & \multicolumn{2}{|c|}{$\mathrm{H}: \mathrm{C}$} & \multicolumn{2}{|c|}{ DBE } & \multicolumn{2}{|c|}{ OM:OC } \\
\hline & Range & Avg. \pm Sd. & Range & Avg. \pm Sd. & Range & Avg. \pm Sd. & Range & Avg. \pm Sd \\
\hline Group I & $0.3-1$ & $0.6 \pm 0.2$ & $1.1-2.0$ & $1.5 \pm 0.2$ & $1-7$ & $3.5 \pm 1.3$ & $1.5-2.4$ & $1.9 \pm 0.2$ \\
\hline Group II & $0.3-0.9$ & $0.5 \pm 0.1$ & $1.2-1.9$ & $1.5 \pm 0.2$ & $2-9$ & $5.3 \pm 1.4$ & $1.5-2.3$ & $1.8 \pm 0.2$ \\
\hline Group III & $0.3-0.8$ & $0.5 \pm 0.1$ & $1.3-1.8$ & $1.6 \pm 0.1$ & $4-10$ & $7.0 \pm 1.6$ & $1.5-2.1$ & $1.8 \pm 0.1$ \\
\hline Group IV & $0.3-0.6$ & $0.5 \pm 0.1$ & $1.4-1.7$ & $1.6 \pm 0.1$ & $6-11$ & $8.6 \pm 1.4$ & $1.6-2.0$ & $1.8 \pm 0.1$ \\
\hline
\end{tabular}

limonene ozonolysis (see Fig. 2b and c) (Lee et al., 2006). SOA growth by the uptake of gas-phase carbonyls has been demonstrated in both experimental (Kroll et al., 2005; Jang and Kamens, 2001) and theoretical studies (Barsanti and Pankow, 2004). Reactive absorption of carbonyl compounds will be further evaluated by the fragmentation analysis in Sect. 3.4.

The relative abundances of the $\mathrm{O}$ homologous series with DBE values of 3 are the most prominent in the mass spectra (Fig. 1h). The formation of an $\mathrm{O}$ homologous series with DBE values of 3 is illustrated in Fig. 3 with multistep oxygen-increasing-reactions. Alkyl radical (XI, $\mathrm{C}_{9} \mathrm{H}_{13} \mathrm{O}_{2}$ ) can be produced by the $\alpha$-cleavage of alkoxy radicals resulting from limonene ozonolysis (Walser et al., 2008). This alkyl radical is converted to another alkyl radical (XIII, $\mathrm{C}_{9} \mathrm{H}_{13} \mathrm{O}_{3}$ ) with one more oxygen atom following oxygenincreasing-reactions $\left(\mathrm{O}_{2}\right.$ addition $\rightarrow$ reactions with $\mathrm{RO}_{2}$ radicals $\rightarrow$ isomerization). If the oxygen-increasing-reactions are repeated on the alkyl radical (XIII, $\mathrm{C}_{9} \mathrm{H}_{13} \mathrm{O}_{3}$ ), alkoxy radicals XIV $\left(\mathrm{C}_{9} \mathrm{H}_{13} \mathrm{O}_{4}\right)$, XV $\left(\mathrm{C}_{9} \mathrm{H}_{13} \mathrm{O}_{5}\right)$, XVI $\left(\mathrm{C}_{9} \mathrm{H}_{13} \mathrm{O}_{6}\right)$ and XVII $\left(\mathrm{C}_{9} \mathrm{H}_{13} \mathrm{O}_{7}\right)$ are produced. These radicals react with $\mathrm{RO}_{2}$ to form the following neutral compounds $\mathrm{C}_{9} \mathrm{H}_{14} \mathrm{O}_{4}$, 

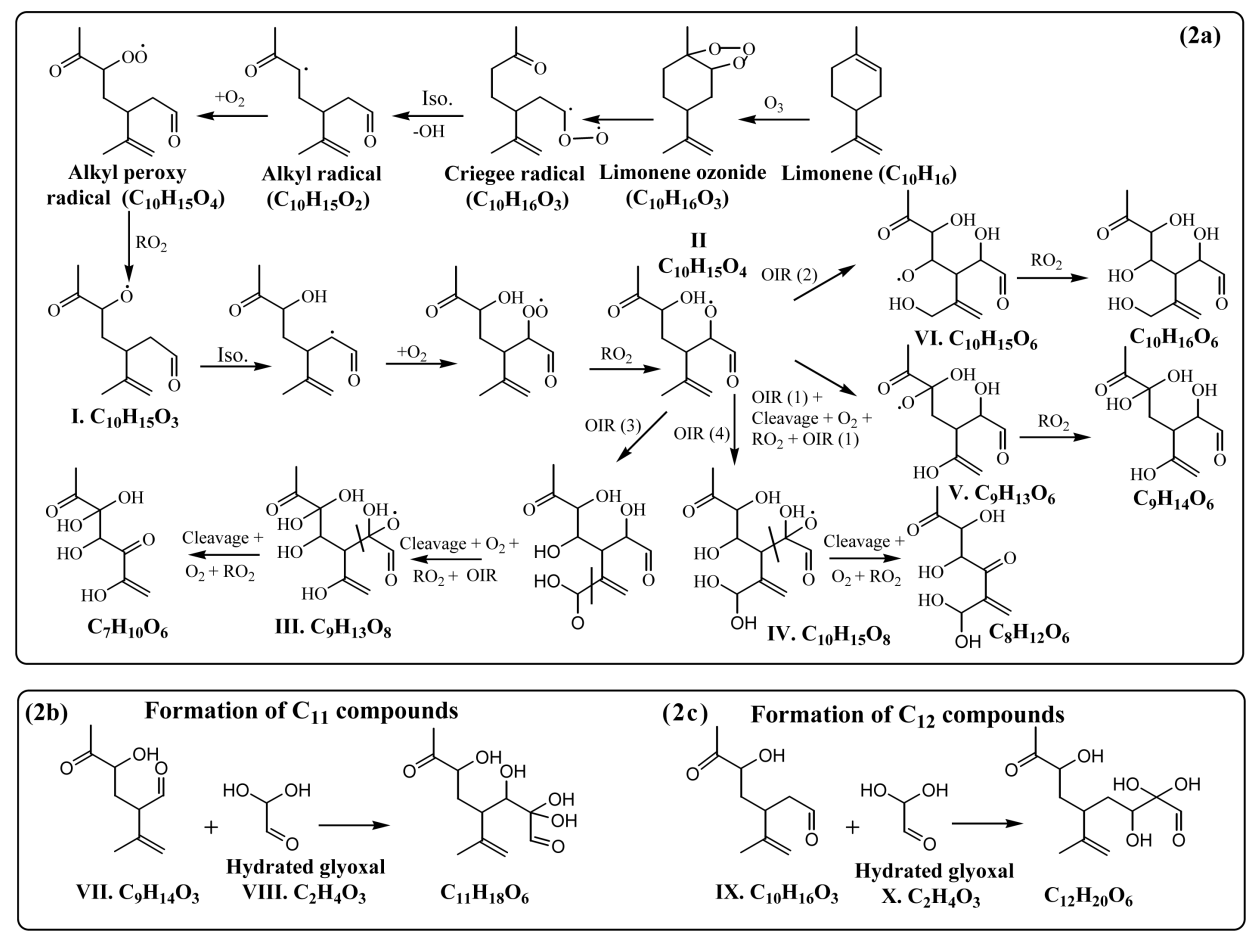

Fig. 2. Depiction of the potential formation mechanisms of $\mathrm{CH}_{2}$ homologous series. (a) Alkoxy radical (I) resulting from the Criegee radical which undergoes oxygen-increasing-reactions (OIR, isomerization of the alkoxy radical $\rightarrow \mathrm{O}_{2}$ addition to the alkyl radical $\rightarrow$ reaction between $\mathrm{RO}_{2}$ radicals) to become an alkoxy radical (II) with an additional oxygen atom. OIR sequence repeats to form alkoxy radicals labeled III, IV, V and VI. The number in the parenthesis beside "OIR" indicates the repetition of OIR sequence. These alkoxy radicals are converted to neutral molecules to form the homologous series. The schematics in (b, $\mathbf{c})$ show organic aerosol formation for $\mathrm{C}_{11}-\mathrm{C}_{12}$ compounds by the reactive uptake of a gas phase carbonyl (e.g., glyoxal).

$\mathrm{C}_{9} \mathrm{H}_{14} \mathrm{O}_{5}, \mathrm{C}_{9} \mathrm{H}_{14} \mathrm{O}_{6}$ and $\mathrm{C}_{9} \mathrm{H}_{14} \mathrm{O}_{7} . \mathrm{C}_{9} \mathrm{H}_{14} \mathrm{O}_{3}$ can be produced by the reactions of alkoxy radicals (XII, $\mathrm{C}_{9} \mathrm{H}_{13} \mathrm{O}_{3}$ ) with $\mathrm{RO}_{2}$ radicals followed by isomerization. Together, they form the homologous series of $\mathrm{C}_{9} \mathrm{H}_{14} \mathrm{O}_{3-7}$.

The formation processes of the homologous series of compounds with DBE values of 4 are shown in Fig. S4. The formation processes are similar to that of the homologous series of compounds with DBE values of 3 with one exception. A ketone is generated instead of an alcohol in the reactions between $\mathrm{RO}_{2}$ radicals in the termination step. The formation processes of the homologous series of compounds with DBE values of 2, which are observed with significant relative abundances (Fig. 1b, g and 1), are less clear. They may result from the hydration of carbonyl groups during the aqueous extraction procedure. However, it appears to be unlikely since some of the identical compounds were previously reported in limonene ozonolysis SOA following non-aqueous extraction procedures (Bateman et al., 2010; Walser et al., 2008). Although the formation processes of some of the species with DBE values of 2 and carbon atom numbers $<10$ can be explained with the previously described processes, the formation of compounds with carbon atom number $>10$ is not clear.

\subsection{Characteristics and formation of high MW SOA}

Similar to the low MW compounds, $\mathrm{CH}_{2}, \mathrm{CH}_{2} \mathrm{O}$ and $\mathrm{O}$ homologous series were observed in each group of the high MW compounds. $\mathrm{CH}_{2}$ and $\mathrm{CH}_{2} \mathrm{O}$ homologous series result from a complex array of species with a variety of unknown structures and thus they are not indicative of the reaction channels nor structural properties (Mazzoleni et al., 2010). The molecular formula characteristics of the limonene ozonolysis SOA components in Groups I, II, III and IV are listed in Table 1. The most prominent DBE values observed in Group I, Group II and Group III are 3, 5 and 7, respectively (Fig. 4). Thus, the prominent differences in the DBE values between groups is 2. Similar DBE delta values were observed in limonene ozonolysis SOA by Bateman et al. (2009). They interpreted it to be associated with a predominance of Criegee radical and hemi-acetal reaction channels over the condensation reaction channels. As they demonstrated, the change of $2 \mathrm{DBE}$ occurs in Criegee and hemiacetal reactions (Fig. S5) and change of 3 DBE occurs in condensation reactions (aldol and esterification) (Fig. S6). However, the change of 2 DBE may also occur in the hydroperoxide reaction channel (Fig. S5); so, this reaction channel may also be responsible for the predominance of the DBE 


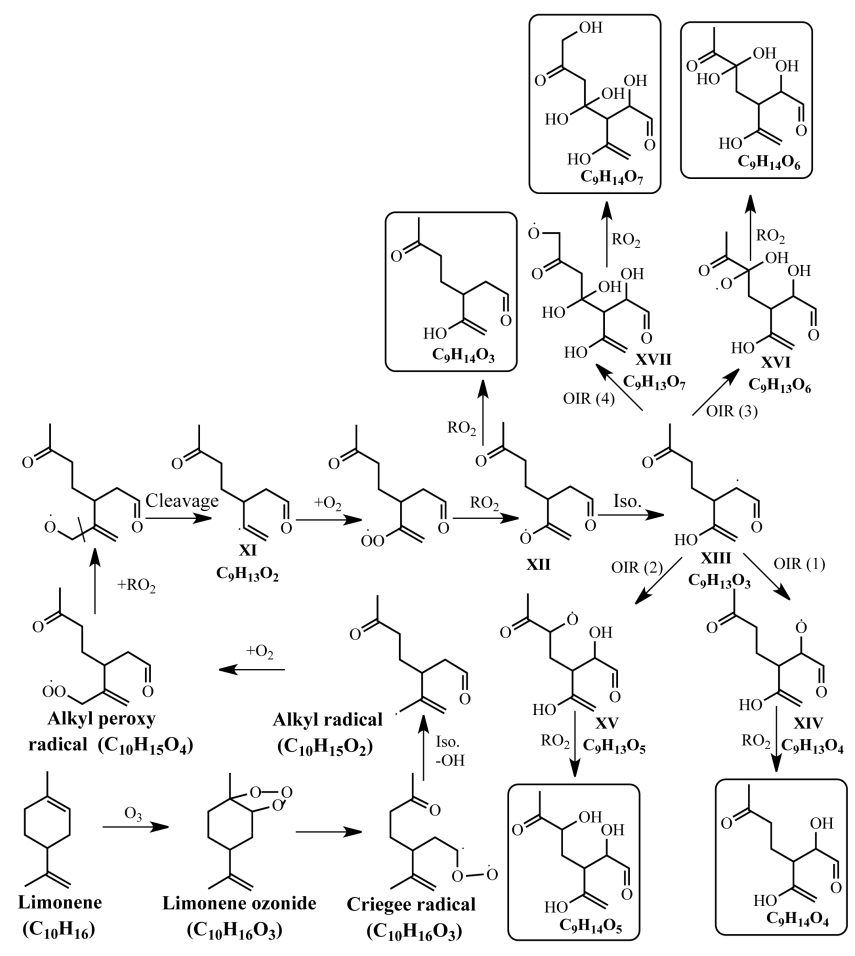

Fig. 3. Illustration depicting the formation of $\mathrm{O}$ homologous series. Alkoxy radical resulting from the Criegee radical could convert to alkyl radical (XI) by cleavage. Oxygen-increasing-reactions (OIR, $\mathrm{O}_{2}$ addition to the alkyl radical $\rightarrow$ reaction between $\mathrm{RO}_{2}$ radicals $\rightarrow$ isomerization of the alkoxy radical) produce an alkyl radical (XIII) with an additional oxygen atom. Further OIR sequences result in alkoxy radicals labeled as XIV, XV and XVI and XVII. They are transformed to neutral molecules by reactions with $\mathrm{RO}_{2}$ and comprise the $\mathrm{O}$ homologous series.

changes observed in limonene SOA. Fragmentation analyses of selected peaks in Sect. 3.4 are used as an additional interpretive tool to determine the relative importance of the reaction channels.

Elemental ratios of hydrogen and oxygen to carbon are useful for classification of complex organic compounds and for evaluating the formation processes of high MW SOA. The van Krevelen diagram, a plot of the $\mathrm{H}: \mathrm{C}$ vs. O:C values for the limonene ozonolysis SOA compounds is shown in Fig. 5. A significant fraction of high abundance compounds was observed with O:C ratios of approximately 0.40.7 and with $\mathrm{H}: \mathrm{C}$ ratios $<1.5$. They are associated with functionalized aliphatic high MW compounds. The average O:C ratio decreases from Group I $(0.59 \pm 0.18)$ to Group II $(0.51 \pm 0.13)$ compounds (Fig. 5b). Significant differences in the O:C and $\mathrm{H}: \mathrm{C}$ ratios of Groups II, III and IV were not observed, although the range of values does decrease with increasing MW. The decrease in O:C ratios from Group I to Group II was interpreted by Reinhardt et al. (2007) as an elimination of $\mathrm{H}_{2} \mathrm{O}$ during the formation of high MW SOA from $\alpha$-pinene ozonolysis following condensation re-

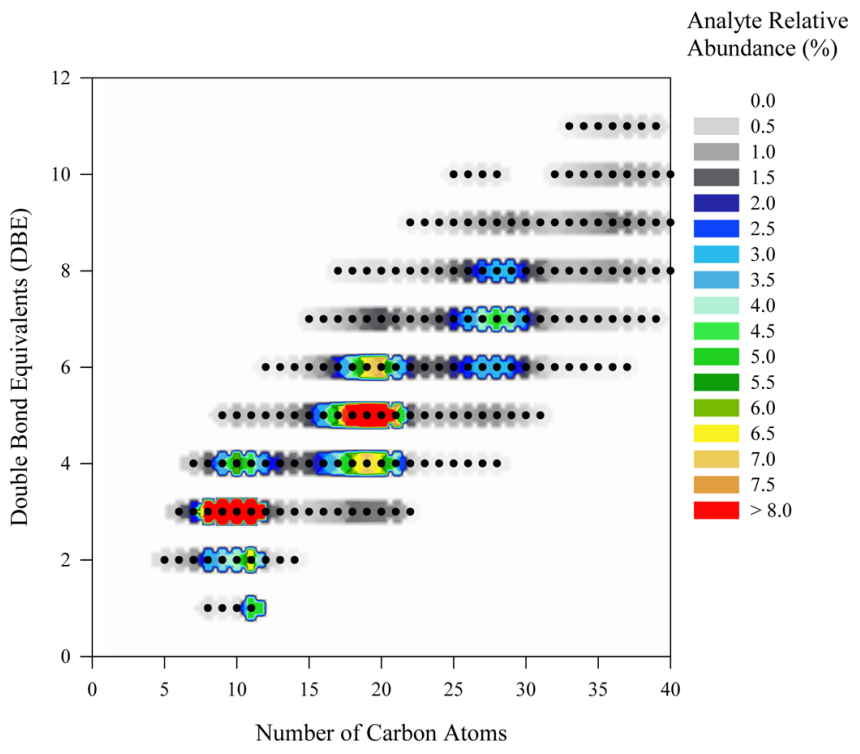

Fig. 4. Double bond equivalents (DBE) versus number of carbon atoms. The color represents the relative abundance of negative ions. Data points common between the samples with all relative abundances are included in the plots.

actions. However if water is eliminated as proposed, it is also expected that the $\mathrm{H}: \mathrm{C}$ ratio will also decrease from Group I $(1.5 \pm 0.20)$ to Group II $(1.5 \pm 0.16)$. We did not observe a change in $\mathrm{H}: \mathrm{C}$ ratios which indicates a lower significance for the condensation reaction channels. These observations and the DBE trends may suggest a higher significance of the hydroperoxide, Criegee radical and hemi-acetal reaction channels. Note, the observed O:C ratio decrease with increasing MW differs from the interpretations of ambient aerosol measurements using high resolution aerosol mass spectrometry (Jimenez et al., 2009). Typically, the O:C ratios of low-volatility oxygenated organic aerosol (representing oligomeric and other high MW compounds) are higher than those of semi-volatile oxygenated organic aerosol (representing comparatively fresh and low MW compounds). This indicates substantial differences either in the ambient atmospheric aerosol composition or in the elemental ratio measurement method.

As discussed, the SOA components observed in Group II and Group III are expected to represent combinations of hydroperoxides, Criegee radicals, and Group I compounds. To evaluate the combinations a reaction matrix was created with several different reaction channels to interpret the formation processes of the high MW compounds. They included 9 limonene derived hydroperoxides (Heaton et al., 2007), 3 limonene derived Criegee radicals (Docherty et al., 2004) and the highly abundant neutral molecules (RA $>1 \%$ ) of Group I. Most of the Group I analytes (71 of 74) have 4 or more oxygen atoms and fragmentation analysis has suggested the presence of structural isomers. For the reactions, 

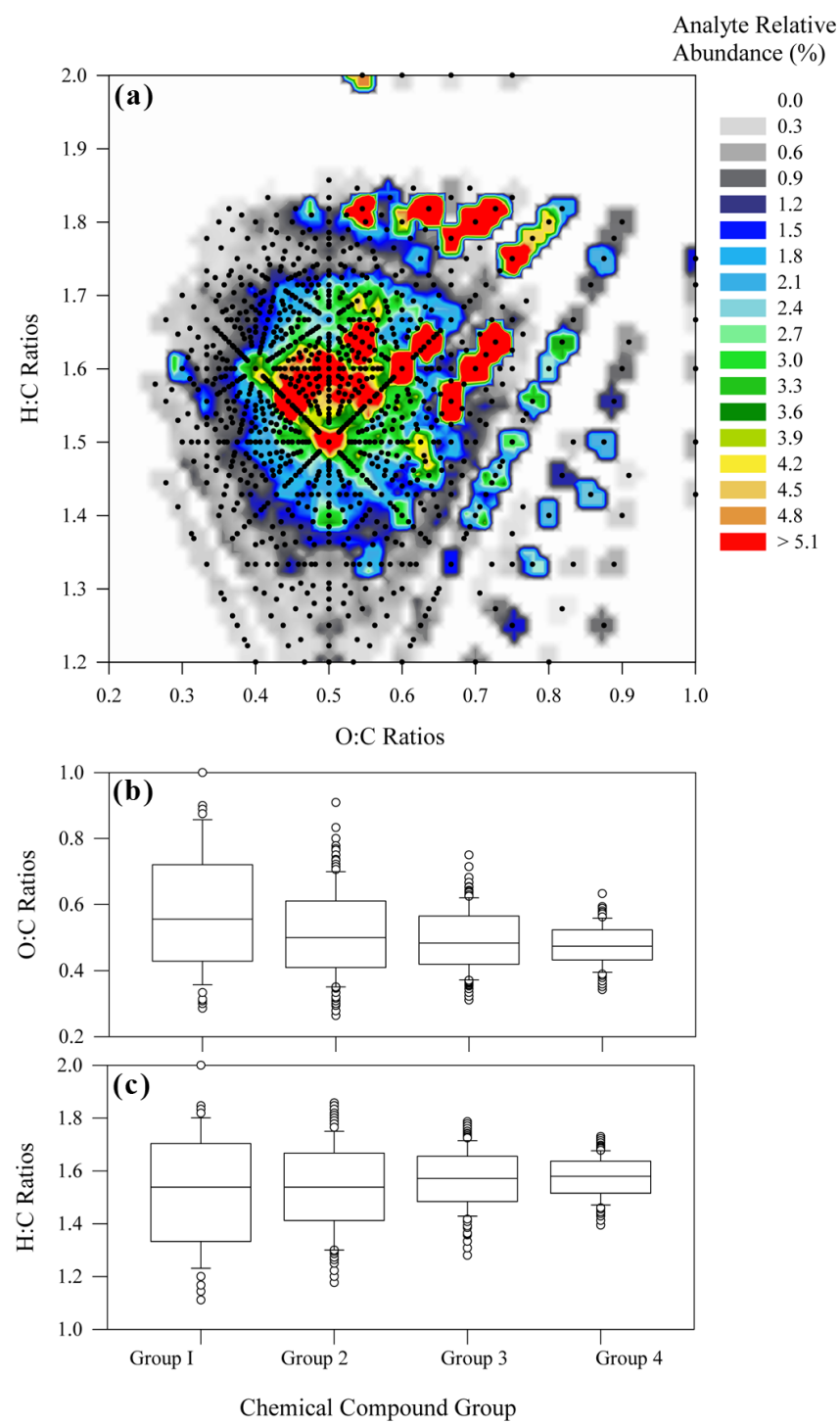

Fig. 5. (a) Depiction of the degree of oxidation for the common negative ions of the samples. Data points have been color coded according to the logarithm of their relative abundances in the mass spectrum. Boxplots (b, c) of O:C and $\mathrm{H}: \mathrm{C}$ ratios are plotted with respect to the defined groups (Group I is $140<m / z<300$, Group II is $300<m / z<500$, Group III is $500<m / z<700$ and Group IV is $700<m / z<850)$.

it was assumed that each of the Group I analytes are structural isomers involving alcohol, ketone and carboxylic acid functional groups. Hydroperoxides and Criegee radicals are expected to react with the neutral molecules leading to the formation of the high MW SOA components. Reactions may also occur between either alcohol and carbonyl functional groups via the hemi-acetal reaction channel or alcohol and carboxylic acid functional groups via the esterification reaction channel. Carbonyl containing compounds react together with the elimination of a water molecule via the aldol condensation reaction channel. The schematics of these reaction processes are shown in Figs. S5 and S6. Using the reaction matrix approach, 152 Group II and 108 Group III compounds matched to the predicted products of the hydroperoxide reaction channel. Likewise, 113 Group II and 198 Group III compounds matched the Criegee radical reaction channel. Similarly, the predicted reaction products of the hemi-acetal channel corresponded to 153 Group II and 119 Group III compounds. Another 144 Group II and 111 Group III compounds matched predicted products of the condensation reaction channel. The percentage of overlap for the reaction channels is very significant; indicating a significant fraction of the matched products could have followed more than 1 reaction channel. More specifically, 88 of 193 predicted Group II products and 91 of 158 predicted Group III products can be explained by all four channels. Overall Criegee radical, hydroperoxide, hemi-acetal, and condensation reaction channels can explain $58 \%, 78 \%, 79 \%$ and $74 \%$ of the Group II compounds and $58 \%, 64 \%, 71 \%$ and $66 \%$ of the Group III compounds, respectively. Reaction channels for the 50 most abundant Group II compounds are shown in Fig. 6. The results indicate that most of the high MW compounds can be formed via multiple reaction channels. A higher matching probability was obtained for the hemi-acetal and condensation reaction channels compared to the Criegee radical and hydroperoxide reaction channels. Similar results were also observed for Group III compounds (see Table S2). The higher matching probability could be related to the higher number of building units for hemi-acetal and condensation reactions compared to the Criegee radical and hydroperoxide reaction channels. To explore this further, the contribution of peak intensities were calculated for the Group II and Group III compounds predicted by the reaction matrix. Although the matching probability is low for Criegee radical and hydroperoxide reactions, they can account for more than $85 \%$ of the total Group II relative abundance and more than $78 \%$ of the total Group III relative abundance. The reaction matrix analysis suggests that none of the presented channels can be excluded as the possible formation mechanisms for the formation of high MW SOA.

\subsection{Structural elucidation of selected ions}

Fragmentation analysis was done for a better understanding of the molecular composition and the formation processes of high MW compounds. Fragmentation of precursor ions within a $2 \mathrm{Da}$ mass range window was performed on the abundant nominal masses of $\mathrm{m} / \mathrm{z} 245, \mathrm{~m} / \mathrm{z}, 401$ and $\mathrm{m} / \mathrm{z} 587$. Due to the complex array of isobaric ions, the isolation of singular precursor ions is not possible (LeClair et al., 2012). It is assumed that a majority of the product ions were generated from the peaks with the greatest initial relative abundances in the isolated mass range.

The product ion mass spectrum for $m / z, 245 \pm 2$ is shown in Fig. 7. The dominant precursor ion is $\mathrm{m} / z, 245.1032$ $\left(\mathrm{C}_{11} \mathrm{H}_{18} \mathrm{O}_{6}\right)$ and there are 9 less abundant isobaric ions at 


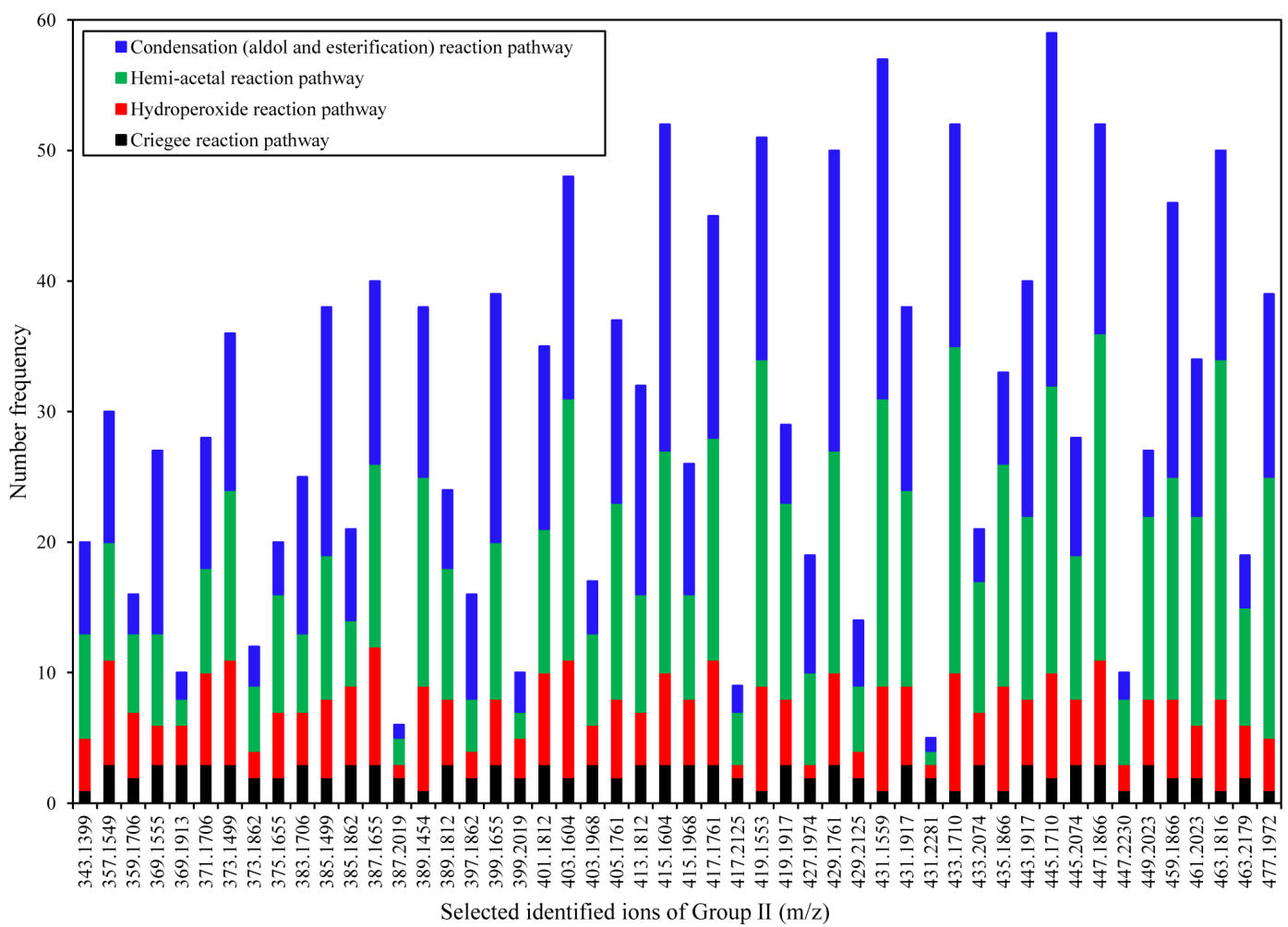

Fig. 6. Formation of the 50 most prominent Group II high MW compounds. The number frequency denotes possible combinations of building units by different reaction channels.

$\mathrm{m} / \mathrm{z} 245$ (inset panel). This compound was previously proposed to be formed by the reactive adsorption of a vapor phase carbonyl as shown in Fig. 2b. Examples of the precursor ions are shown in the lower panel of Fig. 2b. The expected major fragments of this compound and its structural isomers were observed in the product ion spectrum (Fig. 7). Product ions in the high mass range $(\mathrm{m} / \mathrm{z} \geq 165)$ are related to the elimination of $\mathrm{H}_{2} \mathrm{O}, \mathrm{CO}$ and $\mathrm{CO}_{2}$ from the precursor ions. They include peaks at $\mathrm{m} / \mathrm{z} 165, \mathrm{~m} / \mathrm{z}, 183, \mathrm{~m} / \mathrm{z}, 201$, $\mathrm{m} / \mathrm{z} 209, \mathrm{~m} / \mathrm{z} 217$ and $\mathrm{m} / \mathrm{z}$ 227. Formaldehyde $\left(\mathrm{CH}_{2} \mathrm{O}\right)$ addition is a reactive process that results in a stable molecule from which $\mathrm{CH}_{2} \mathrm{O}$ elimination is not possible during fragmentation analysis. Additional peaks related to fragmentation at the $\beta$-carbon relative to the carboxyl or carbonyl groups via the McLafferty rearrangement in the structural isomers (lower panels, b, c and d); resulting in the following product ions: $\mathrm{m} / \mathrm{z} 169, \mathrm{~m} / \mathrm{z}, 75, \mathrm{~m} / \mathrm{z} 73, \mathrm{~m} / \mathrm{z} 171, \mathrm{~m} / \mathrm{z} 59$, $\mathrm{m} / \mathrm{z}, 185, \mathrm{~m} / \mathrm{z}, 89, \mathrm{~m} / \mathrm{z}, 155, \mathrm{~m} / \mathrm{z} 105$ and $\mathrm{m} / \mathrm{z}, 139$. Fragmentation at the $\alpha$-position relative to the $\mathrm{OH}$ group in a structural isomer (lower panel, e) can produce the following product ions: $\mathrm{m} / \mathrm{z}, 157, \mathrm{~m} / \mathrm{z} 87, \mathrm{~m} / \mathrm{z} 99, \mathrm{~m} / \mathrm{z} 117$ and $\mathrm{m} / \mathrm{z}$ 127. Similar neutral molecule eliminations may explain the other dominant ion at $\mathrm{m} / \mathrm{z}$ 185. Its mass spectrum and fragmentation processes are provided in Fig. S7a.

The results of the reaction matrix indicate that the peak at $m / z 401.1817\left(\mathrm{C}_{19} \mathrm{H}_{30} \mathrm{O}_{9}\right)$ and $m / z 401.2179\left(\mathrm{C}_{20} \mathrm{H}_{34} \mathrm{O}_{8}\right)$ can be formed by all 4 of the evaluated reaction channels. Thus, fragmentation analysis was done to evaluate them. The product ion mass spectrum of $m / z 401 \pm 2$ is shown in Fig. 8a. Although there are 13 isobaric peaks within $\mathrm{m} / \mathrm{z} 401$, the product ions are assumed to be predominantly from the 2 most prominent precursor ions $\mathrm{m} / z, 401.1817$ and $\mathrm{m} / \mathrm{z}$ 401.219. The building blocks (shown in the figure inset) associated with hydroperoxide, Criegee radical and hemi-acetal reaction channels can explain most of the prominent peaks between $\mathrm{m} / z, 143$ and $\mathrm{m} / \mathrm{z} 245$. The building units for the most of the condensation reaction channels (aldol and esterification) are not observed in the product mass spectra of $m / z 401 \pm 2$. Similar results were also obtained for other prominent ions at $m / z 357 \pm 2, m / z 387 \pm 2$, and $m / z 417 \pm 2$. Their product ion mass spectra are shown in Fig. S7b-d. The results further support the importance of hydroperoxide, Criegee radical and hemi-acetal reactions over condensation reactions for the formation of the high MW compounds in Group II. The prominent product ions at the high mass region are $m / z, 303$, $m / z 321, m / z 339, m / z 365$ and $m / z 383$. They are related to neutral molecule eliminations such as $\mathrm{H}_{2} \mathrm{O}, \mathrm{CO}_{2}$ and combinations of them from the precursor ions. The product ions $<m / z 140$ likely result from secondary fragmentation of the building units relative to $m / z 401$. Typical fragmentation processes of the building units have been shown previously in Fig. 7. 

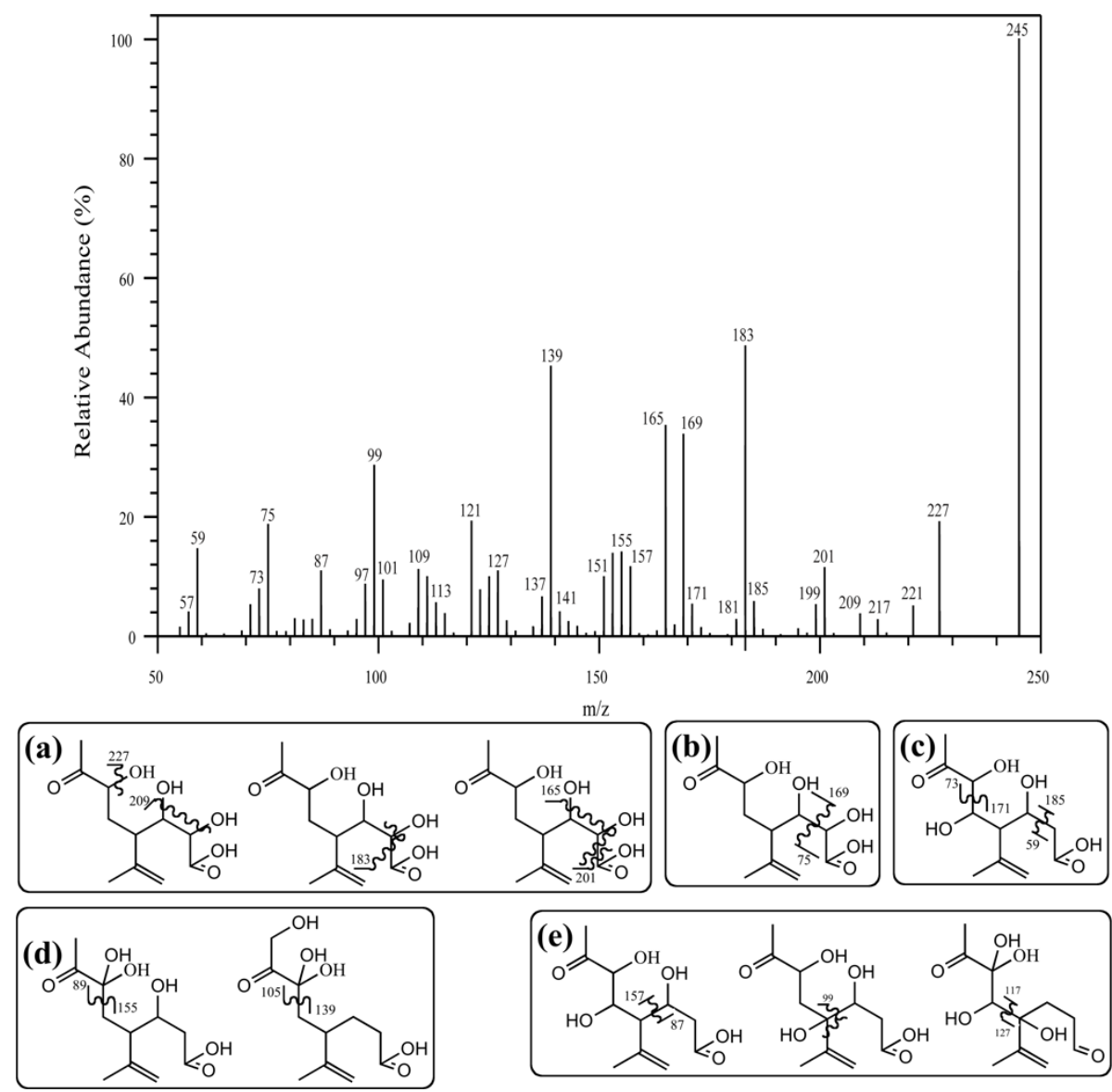

Fig. 7. Product ion mass spectrum of the fragmentation of $\mathrm{m} / \mathrm{z}, 245 \pm 2$. Infrared multiphoton dissociation technique (IRMPD) was used for the fragmentation of peaks using FT ICR-MS. Proposed structural isomers and their fragmentation processes are shown in the lower panel (a-e).

The dominant Group III ions at $\mathrm{m} / z 587.2343\left(\mathrm{C}_{27} \mathrm{H}_{40}\right.$ $\left.\mathrm{O}_{14}\right), m / z 587.2708\left(\mathrm{C}_{28} \mathrm{H}_{44} \mathrm{O}_{13}\right)$ and $m / z 587.3074\left(\mathrm{C}_{29} \mathrm{H}_{48}\right.$ $\mathrm{O}_{12}$ ) may have resulted from several different combinations of building units. Following the condensation reaction channels, the MW of at least one building unit is $>230$ in $80 \%$ of the combinations. The product ions of these precursors are much less abundant in the mass spectrum. Similar results were also obtained from the fragmentation of $\mathrm{m} / \mathrm{z}, 541 \pm 2$ (Fig. S7e). These results further suggest a greater importance of the hydroperoxide, Criegee radical and hemi-acetal reaction channels in the formation of high MW compounds. The product ions of the high mass region at $\mathrm{m} / \mathrm{z} 569, \mathrm{~m} / \mathrm{z}, 551$ and $\mathrm{m} / \mathrm{z}, 515$ are associated with the elimination of $\mathrm{H}_{2} \mathrm{O}, \mathrm{CO}_{2}$ and combinations of them. The product ions in the middle mass region such as $m / z, 401, m / z, 399, \mathrm{~m} / z, 385, \mathrm{~m} / \mathrm{z} 369, \mathrm{~m} / \mathrm{z} 355$, $\mathrm{m} / \mathrm{z} 339, \mathrm{~m} / \mathrm{z} 327$ and $\mathrm{m} / \mathrm{z}, 315$ are due to the loss of neutral building units including $186 \mathrm{Da}, 188 \mathrm{Da}, 202 \mathrm{Da}, 218 \mathrm{Da}$, $232 \mathrm{Da}, 248 \mathrm{Da}$, and $260 \mathrm{Da}$, respectively. Most of the prominent peaks in the middle of the product spectra $\mathrm{m} / \mathrm{z} 143-300$ are related to secondary fragmentation of the building units of the precursors. They might have resulted from the charac- teristic fragmentation processes of the building units of the high MW compounds as shown in Fig. 7.

The product ions in Fig. 8a and b are associated with Group II and Group III precursors, respectively. The range of $\mathrm{m} / \mathrm{z} 300-450$ was observed only in the product ion spectra of the Group III compounds. This suggests the presence of an additional building unit in the molecules of Group III compounds. Most of the building units in the range of $\mathrm{m} / \mathrm{z}, 150-300$ are common in the product spectra of Group II and Group III compounds; however, their relative abundances are different. The results suggest the participation of different amounts of the building units in the formation of high MW compounds.

\section{Conclusions}

Approximately 1200 molecular formulas were identified in the SOA of laboratory generated limonene ozonolysis using ultrahigh-resolution Fourier transform ion cyclotron resonance mass spectrometry (FT-ICR-MS). Four characteristic groups of high relative abundance analytes were observed 


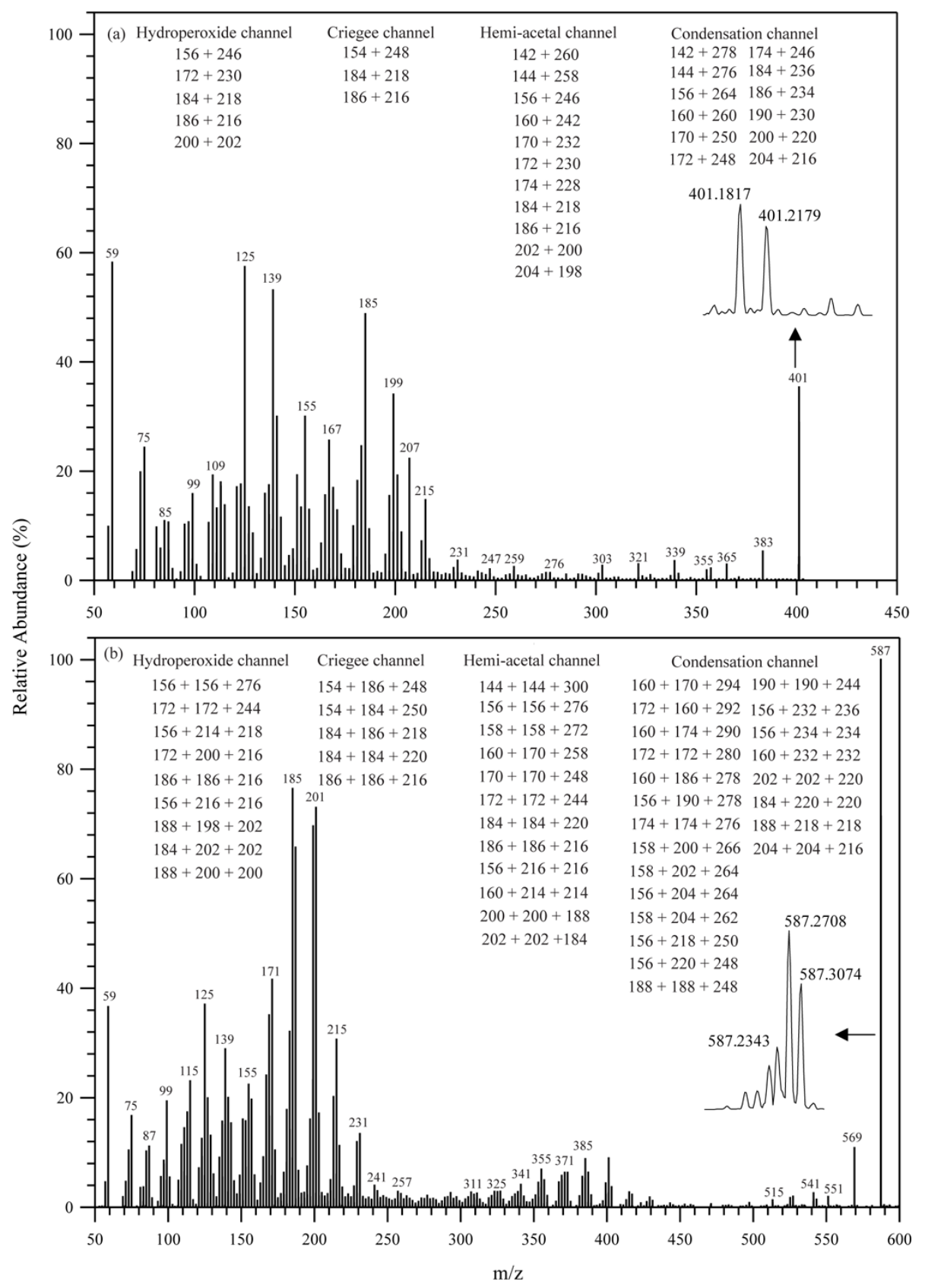

Fig. 8. Product ion mass spectra for the fragmentation of $m / z 401 \pm 2$ in (a) and $m / z 587 \pm 2$ in (b). Infrared multiphoton dissociation technique (IRMPD) was used for the fragmentation of isobaric masses using FT ICR-MS. The combinations of building units for the reaction channels that form $\mathrm{m} / \mathrm{z} 401.1817$ and $\mathrm{m} / \mathrm{z} 401.2179$ are shown in (a). The combinations of building units for the reaction channels that form $\mathrm{m} / \mathrm{z}$ 587.2343, $\mathrm{m} / \mathrm{z} 587.2708$ and $\mathrm{m} / \mathrm{z} 587.3074$ are shown in (b).

(Group I, II, III, and IV). The observed homologous series in the low MW region (Group I) are predicted by a combination of functionalization (multistep oxygen-increasingreactions) and fragmentation (bond scission) of alkoxy radicals and reactive uptake of gas phase carbonyls. The presence of $\mathrm{C}_{11} \mathrm{H}_{18} \mathrm{O}_{6}$ corresponding to $\mathrm{m} / z 245$, the most prominent negative ion in the mass spectra, provides evidence for aerosol formation by the reactive uptake of vapor phase car- bonyls (such as formaldehyde or glyoxal). Conflicting evidence for the dominant reaction channels in the formation of high MW compounds was further investigated using a comprehensive reaction matrix and fragmentation analysis. The highest frequency of matches between the predicted compounds and the identified compounds related to the hemiacetal and condensation (aldol and esterification) reaction channels. This might be related to the higher number of 
building units for the reactions compared to the Criegee radical and hydroperoxide reactions. Although the number of matches are lower for Criegee radical and hydroperoxide reaction channels, the high relative abundances of the building blocks suggests they may account for more than $85 \%$ of total Group II relative abundance and more than $78 \%$ of total Group III relative abundance. Fragmentation analysis suggests that the building blocks associated with hydroperoxide, Criegee radical and hemi-acetal reaction channels can explain most of the prominent product ions whereas building blocks involving the condensation (aldol and esterification) reaction channels are not observed as prominent product ions. Although this observation is based on a small number of compounds. Overall, this comprehensive approach involving DBE, elemental ratios, reaction matrix and fragmentation analysis indicates a greater importance of noncondensation reactions (hydroperoxide, Criegee radical and hemiactal) over the condensation (aldol and esterification) reactions for the formation of high MW compounds. Among the non-condensation reactions, the hemi-acetal reactions appear to be the most dominant followed by hydrperoxide and Criegee radical reactions.

\section{Supplementary material related to this article is available online at: http://www.atmos-chem-phys.net/12/ 5523/2012/acp-12-5523-2012-supplement.zip.}

Acknowledgements. The authors thank Melissa Soule and Elizabeth Kujawinski of the Woods Hole Oceanographic Institution Mass Spectrometry Facility for instrument time and assistance with data acquisition. We also thank Giuseppe Petrucci of the University of Vermont for helpful discussions. Major funding for this work was provided by the Los Alamos National Laboratory, Laboratory Directed Research and Development program via a subcontract. S. Kundu thanks David and Valeria Pruett for fellowship support via the Department of Chemistry at Michigan Tech.

Edited by: J. H. Seinfeld

\section{References}

Barsanti, K. C. and Pankow, J. F.: Thermodynamics of the formation of atmospheric organic particulate matter by accretion reactions - part 1: aldehydes and ketones, Atmos. Environ., 38, 4371-4382, 2004.

Barsanti, K. C. and Pankow, J. F.: Thermodynamics of the formation of atmospheric organic particulate matter by accretion reactions: Part 2: Dialdehydes, methylglyoxal, and diketones, Atmos. Environ., 39, 6597-6607, 2005.

Bateman, A., Walser, M., Laskin, J., Laskin A., and Nizkorodov, S.: The Effect of Solvent on the Analysis of Secondary Organic Aerosol Using Electrospray Ionization Mass Spectrometry, Environ. Sci. Technol., 42, 7341-7346, 2008.

Bateman, A. P., Nizkorodov, S. A., Laskin, J., and Laskin, A.: Timeresolved molecular characterization of limonene/ozone aerosol using high-resolution electrospray ionization mass spectrometry, Phys. Chem. Chem. Phys., 11, 7931-7942, 2009.

Docherty, K. S., Wilbur, W., Lim, Y. B., and Ziemann, P. J.: Contributions of organic peroxides to secondary aerosol formed from reactions of monoterpenes with $\mathrm{O}_{3}$, Environ. Sci. Technol., 39, 4049-4059, 2004.

Fuzzi, S., Andreae, M. O., Huebert, B. J., Kulmala, M., Bond, T. C., Boy, M., Doherty, S. J., Guenther, A., Kanakidou, M., Kawamura, K., Kerminen, V.-M., Lohmann, U., Russell, L. M., and Pöschl, U.: Critical assessment of the current state of scientific knowledge, terminology, and research needs concerning the role of organic aerosols in the atmosphere, climate, and global change, Atmos. Chem. Phys., 6, 2017-2038, doi:10.5194/acp-62017-2006, 2006.

Gao, S., Ng, A. L., Keywood, M., Varutbangkul, V., Bahreini, R., Nenes, A., He, J. W., Yoo, K. Y., Beauchamp, J. L., Hodyss, R. P., Flagan, R. C., and Seinfeld, J. H.: Particle Phase Acidity and Oligomer Formation in Secondary Organic Aerosol, Environ. Sci. Technol., 38, 6582-6589, 2004.

Geddes, S., Nichols, B., Flemer Jr., S., Eisenhauer, J., Zahardis, J., and Petrucci, G. A.: Near-infrared laser desorption/ionization aerosol mass spectrometry for investigating organic aerosols under low loading conditions, Anal. Chem., 82, 7915-7923, 2010.

Hallquist, M., Wenger, J. C., Baltensperger, U., Rudich, Y., Simpson, D., Claeys, M., Dommen, J., Donahue, N. M., George, C., Goldstein, A. H., Hamilton, J. F., Herrmann, H., Hoffmann, T., Iinuma, Y., Jang, M., Jenkin, M. E., Jimenez, J. L., Kiendler-Scharr, A., Maenhaut, W., McFiggans, G., Mentel, Th. F., Monod, A., Prévôt, A. S. H., Seinfeld, J. H., Surratt, J. D., Szmigielski, R., and Wildt, J.: The formation, properties and impact of secondary organic aerosol: current and emerging issues, Atmos. Chem. Phys., 9, 5155-5236, doi:10.5194/acp-9-51552009, 2009.

Hamilton, J. F., Lewis, A. C., Reynolds, J. C., Carpenter, L. J., and Lubben, A.: Investigating the composition of organic aerosol resulting from cyclohexene ozonolysis: low molecular weight and heterogeneous reaction products, Atmos. Chem. Phys., 6, 49734984, doi:10.5194/acp-6-4973-2006, 2006.

Heaton, K. J., Dreyfus, M. A., Wang, S., and Johnston, M. V.: Oligomers in the early stage of biogenic secondary organic aerosol formation and growth, Environ. Sci. Technol., 41, 61296136, doi:10.1021/es070314n, 2007.

Heaton, K. J., Sleighter, R. L., Hatcher, P. G., Hall, W. A. I., and Johnston, M. V.: Composition domains in monoterpene secondary organic aerosol, Environ. Sci. Technol., 43, 7797-7802, 2009.

Iinuma, Y., Böge, O., Gnauk, T., and Herrmann, H.: Aerosolchamber study of the $\alpha$-pinene/ $\mathrm{O}_{3}$ reaction: Influence of particle acidity on aerosol yields and products, Atmos. Environ., 38, 761-773, 2004.

Jang, M. and Kamens, R. M.: Atmospheric Secondary Aerosol Formation by Heterogeneous Reactions of Aldehydes in the Presence of a Sulfuric Acid Aerosol Catalyst, Environ. Sci. Technol., 35, 4758-4766, 2001.

Jimenez, J. L., Canagaratna, M. R., Donahue, N. M., Prevot, A. S. H., Zhang, Q., Kroll, J. H., DeCarlo, P. F., Allan, J. D., Coe, H., Ng, N. L., Aiken, A. C., Docherty, K. S., Ulbrich, I. M., Grieshop, A. P., Robinson, A. L., Duplissy, J., Smith, J. D., Wilson, K. R., Lanz, V. A., Hueglin, C., Sun, Y. L., Tian, J., 
Laaksonen, A., Raatikainen, T., Rautiainen, J., Vaattovaara, P., Ehn, M., Kulmala, M., Tomlinson, J. M., Collins, D. R., Cubison, M. J., Dunlea, E. J., Huffman, J. A., Onasch, T. B., Alfarra, M. R., Williams, P. I., Bower, K., Kondo, Y., Schneider, J., Drewnick, F., Borrmann, S., Weimer, S., Demerjian, K., Salcedo, D., Cottrell, L., Griffin, R., Takami, A., Miyoshi, T., Hatakeyama, S., Shimono, A., Sun, J. Y., Zhang, Y. M., Dzepina, K., Kimmel, J. R., Sueper, D., Jayne, J. T., Herndon, S. C., Trimborn, A. M., Williams, L. R., Wood, E. C., Middlebrook, A. M., Kolb, C. E., Baltensperger, U., and Worsnop, D. R.: Evolution of organic aerosols in the atmosphere, Science, 326, 1525-1529, 2009.

Jonsson, Å. M., Hallquist, M., and Ljungström, E.: The effect of temperature and water on secondary organic aerosol formation from ozonolysis of limonene, $\Delta^{3}$-carene and $\alpha$-pinene, Atmos. Chem. Phys., 8, 6541-6549, doi:10.5194/acp-8-6541-2008, 2008.

Kalberer, M., Paulsen, D., Sax, M., Steinbacher, M., Dommen, J., Fisseha, R., and Prevot, A. S. H.: Frankevich, V., Zenobi, R., Baltensperger, U.: Identification of polymers as major components of atmospheric organic aerosols, Science, 303, 1659-1662, 2004.

Kanakidou, M., Seinfeld, J. H., Pandis, S. N., Barnes, I., Dentener, F. J., Facchini, M. C., Van Dingenen, R., Ervens, B., Nenes, A., Nielsen, C. J., Swietlicki, E., Putaud, J. P., Balkanski, Y., Fuzzi, S., Horth, J., Moortgat, G. K., Winterhalter, R., Myhre, C. E. L., Tsigaridis, K., Vignati, E., Stephanou, E. G., and Wilson, J.: Organic aerosol and global climate modelling: a review, Atmos. Chem. Phys., 5, 1053-1123, doi:10.5194/acp-5-1053-2005, 2005.

Koch, B. P., Witt, M., Engbrodt, R., Dittmar, T., and Kattner, G.: Molecular formulae of marine and terrigenous dissolved organic matter detected by electrospray ionization Fourier transform ion cyclotron resonance mass spectrometry, Geochim. Cosmochim. Ac., 69, 3299-3308, 2005.

Kroll, J. H., Ng, N. L., Murphy, S. M., Varutbangkul, V., Flagan, R. C., and Seinfeld, J. H.: Chamber studies of secondary organic aerosol growth by reactive uptake of simple carbonyl compounds, J. Geophys. Res.-Atmos., 110, D23207, doi:10.1029/2005JD006004, 2005.

Kujawinski, E. B., Freitas, M. A., Zang, X., Hatcher, P. G., GreenChurch, K. B., and Jones, R. B.: The application of electrospray ionization mass spectrometry (ESI-MS) to the structural characterization of natural organic matter, Org. Geochem., 33, 171$180,2002$.

LeClair, J. P., Collett, J. L., and Mazzoleni, L. R.: Fragmentation analysis of water-soluble atmospheric organic matter using ultrahigh-resolution mass spectrometry, Environ. Sci. Technol., 46, 4312-4322, 2012.

Lee, A., Goldstein, A. H., Kroll, J. H., Ng, N. L., Varutbangkul, V., Flagan, R. C., and Seinfeld, J. H.: Gas-phase products and secondary aerosol yields from the photooxidation of 16 different terpenes, J. Geophys. Res., 111, D17305, doi:10.1029/2006JD007050, 2006.

Leungsakul, S., Jaoui, M., and Kamens, R. M.: Kinetic mechanism for predicting secondary organic aerosol formation from the reaction of d-limonene with ozone, Environ. Sci. Technol., 39, 9583-9594, doi:10.1021/es0492687, 2005.

Liao, H., Henze, D. K., Seinfeld, J. H., Wu, S., and Mickley, L. J.: Biogenic secondary organic aerosol over the United States: Comparison of climatological simulations with observations, J.
Geophys. Res., 112, D06201, doi:10.1029/2006JD007813, 2007. McLafferty, F. W. and Turecek, F.: Interpretation of Mass Spectra, 4th Edn., University Science Books, Sausalito, CA, p. 371, 1993.

Mazzoleni, L. R., Ehrmann, B. M., Shen, X., Marshall, A. G., and Collett, J. L.: Water-soluble atmospheric organic matter in fog: Exact masses and chemical formula identification by ultrahigh-resolution Fourier transform ion cyclotron resonance mass spectrometry, Environ. Sci. Technol., 44, 3690-3697, doi:10.1021/es903409k, 2010.

Putman, A., Offenberg, J. H., Rebeka, F., Kundu, S., Rahn, T., and Mazzoleni, L. R.: Ultrahigh-resolution FT-ICR mass spectrometry of $\alpha$-pinene ozonolysis SOA, Atmos. Environ., 46, 164-172, doi:10.1016/j.atmosenv.2011.10.003, 2011.

Reinhardt, A., Emmenegger, C., Gerrits, B., Panse, C., Dommen, J., Baltensperger, U., Zenobi, R., and Kalberer, M.: Ultrahigh mass resolution and accurate mass measurements as a tool to characterize oligomers in secondary organic aerosols, Anal. Chem., 79, 4074-4082, doi:10.1021/ac062425v, 2007.

Sadezky, A., Winterhalter, R., Kanawati, B., Römpp, A., Spengler, B., Mellouki, A., Le Bras, G., Chaimbault, P., and Moortgat, G. K.: Oligomer formation during gas-phase ozonolysis of small alkenes and enol ethers: new evidence for the central role of the Criegee Intermediate as oligomer chain unit, Atmos. Chem. Phys., 8, 2667-2699, doi:10.5194/acp-8-2667-2008, 2008.

Salma, I., Ocskay, R., and Láng, G. G.: Properties of atmospheric humic-like substances - water system, Atmos. Chem. Phys., 8, 2243-2254, doi:10.5194/acp-8-2243-2008, 2008.

Schaub, T. M., Hendrickson, C. L., Quinn, J. P., Rodgers, R. P., and Marshall, A. G.: Instrumentation and method for ultrahigh resolution field desorption ionization Fourier transform ion cyclotron resonance mass spectrometry of nonpolar species, Anal. Chem., 77, 1317-1324, 2005.

Sleighter, R. L., Liu, Z., Xue, J., and Hatcher, G. P.: Multivariate statistical approaches for the characterization of dissolved organic matter analyzed by ultrahigh resolution mass spectrometry, Environ. Sci. Technol., 44, 7576-7582, 2010.

Soule, M. C., Longnecker, K., Giovannoni, S. J., and Kujawinski, E. B.: Impact of instrument and experiment parameters on reproducibility of ultrahigh resolution ESI FT-ICR mass spectra of natural organic matter, Org. Geochem., 41, 725-733, 2010.

Stroud, C., Makar, P., Karl, T., Guenther, A., Geron, C., Turnipseed, A., Nemitz, E., Baker, B., Potosnak, M., and Fuentes, J. D.: Role of canopy-scale photochemistry in modifying biogenicatmosphere exchange of reactive terpene species: Results from the celtic field study, J. Geophys. Res., 110, D17303, doi:10.1029/2005jd005775, 2005.

Surratt, J. D., Murphy, S. M., Kroll, J. H., Ng, N. L., Hildebrandt, L., Sorooshian, A., Szmigielski, R., Vermeylen, R., Maenhaut, W., Claeys, M., Flagan, R. C., and Seinfeld, J. H.: Chemical composition of secondary organic aerosol formed from the photooxidation of isoprene, J. Phys. Chem. A, 110, 9665-9690, doi:10.1021/jp061734m, 2006.

Tolocka, M. P., Jang, M., Ginter, J. M., Cox, F. J., Kamens, R. M., and Johnston, M. V.: Formation of Oligomers in Secondary Organic Aerosol, Environ. Sci. Technol., 38, 1428-1434, 2004.

Tolocka, M. P., Heaton, K. J., Dreyfus, M. A., Wang. S., Zordan, C. A., Saul, T. D., and Johnston, M. V.: Chemistry of Particle Inception and Growth during $\alpha$-Pinene Ozonolysis, Environ. Sci. Technol., 40, 1843-1848, 2006. 
Walser, M. L., Desyaterik, Y., Laskin, J., Laskin, A., and Nizkorodov, S. A.: High-resolution mass spectrometric analysis of secondary organic aerosol produced by ozonation of limonene, Phys. Chem. Chem. Phys., 10, 1009-1022, 2008.

Went, F. W.: Blue hazes in the atmosphere, Nature, 187, 641-643, 1960.
Ziemann, P. J.: Aerosol products, mechanisms, and kinetics of heterogeneous reactions of ozone with oleic acid in pure and mixed particles, Faraday Discuss., 130, 469-490, doi:10.1039/B417502F, 2005. 